\title{
HPLC Method Development and Validation of S(-)-Carvedilol from API and Formulations
}

\author{
Ettireddy Swetha, Chandupatla Vijitha, Ciddi Veeresham* \\ University College of Pharmaceutical Sciences, Kakatiya University, Warangal, India \\ Email: ${ }^{*}$ ciddiveeresham@yahoo.co.in
}

Received 24 February 2015; accepted 9 April 2015; published 13 April 2015

Copyright (C) 2015 by authors and Scientific Research Publishing Inc.

This work is licensed under the Creative Commons Attribution International License (CC BY). http://creativecommons.org/licenses/by/4.0/

c) (i) Open Access

\begin{abstract}
A simple chiral HPLC method was developed and validated for quantification of S(-)-Carvedilol in Active Pharmaceutical Ingredient (API) and marketed tablet formulation of racemic Carvedilol. Chiral resolution of enantiomers of Carvedilol was achieved on Phenomenex Lux-cellulose-4 (250 $\mathrm{mm} \times 4.6 \mathrm{~mm} ; \boldsymbol{\mu}$ particle size) chiral column by using a mobile phase, Isopropanol and $\mathrm{n}$-Heptane $(60: 40 \mathrm{v} / \mathrm{v})$, at a flow rate of $1.0 \mathrm{ml} / \mathrm{min}$ and by employing $\mathrm{UV}$ detection at $254 \mathrm{~nm}$ wavelength. The method was validated according to the ICH guidelines and was proved to be specific, linear, precise and accurate for the analysis of S(-)-Carvedilol.
\end{abstract}

\section{Keywords}

\section{S(-)-Carvedilol, Chiral HPLC, Chiral Resolution, API, Validation}

\section{Introduction}

Carvedilol, 1-(4-carbazolyloxy)-3-(2-(2-methoxy)ethylamino)-2-propanol [1], has an asymmetric carbon atom, which gives rise to $\mathrm{S}(-)$ - and $\mathrm{R}(+)$-enantiomers [2]. It is a non-selective, $\beta$-adrenergic receptor antagonist and an $\alpha 1$-adrenoceptor blocker. Though the racemic mixture of Carvedilol is administered clinically, $\beta$-adrenoceptor blocking activity of the S(-)-enantiomer is about 200-fold higher than that of the $\mathrm{R}(+)$-enantiomer while the $\alpha 1$-adrenoceptor blocking activity is same for both enantiomers [1]. In addition it is a powerful anti-oxidant; it can protect major organs like heart, kidneys, brain, vasculature, etc. from damage and hence is used in the treatment of chronic hypertension [3]. On oral dosing of racemic Carvedilol, the unbound fraction of S(-)-enantiomer is higher than that of the $\mathrm{R}(+)$-enantiomer and hence $\mathrm{S}(-)$ - gets distributed predominantly in all tissues

\footnotetext{
*Corresponding author.
}

How to cite this paper: Swetha, E., Vijitha, C. and Veeresham, C. (2015) HPLC Method Development and Validation of S(-)-Carvedilol from API and Formulations. American Journal of Analytical Chemistry, 6, 437-445. 
like heart, lungs, liver, kidneys and is metabolized faster than $\mathrm{R}(+)$-enantiomer [4]. It possesses calcium channel blocking effect by inhibiting voltage-dependent L-type $\mathrm{Ca}^{2+}$ in vascular smooth muscle cells [5]. It is also used to treat ischemic heart disease and congestive heart failure [1]. Cardiac hypertrophy is the most dominant predictor for the heart failure and is a homeostatic response to elevate after load which develops due to pressure overload. This can be significantly regressed by S(-)-Carvedilol with less effect on normal heart and liver while the $\mathrm{R}(+)$-Carvedilol possesses significant risk of hepatotoxicity. Therefore the overall cardioprotective action of $\mathrm{S}(-)$-Carvedilol is more and hepatotoxicity is less when compared to that of racemic and R(+)-Carvedilol [6]. In most of the cases, racemic mixtures are more preferred for oral administration than those of the enantiomer because of high cost and difficulty in selective synthesis of one optical isomer [7]. Hence there is a need to develop a validated method for the analysis of S(-)-Carvedilol from API and marketed formulations.

To date, many methods are developed for the enantioselective analysis of Carvedilol which include derivatization with enantiomerically pure chiral reagents resulting in the formation of diastereomeric derivatives (indirect methods) or the use of chiral stationary phases (direct methods). Indirect methods reported are by employing various reagents for chiral derivatization of Carvedilol [8]-[12] using RP-HPLC (Reverse Phase-High Performance Liquid Chromatography) with UV (Ultra Violet) detection [8] or HPLC with fluorescence detection or liquid chromatography-tandem mass spectrometry (LC-MS/MS) [13]. Direct methods involve the use of chiral stationary-phase columns or mobile phases containing chiral additives. Different columns such as Phenomenex 3022 (Torrance, CA) [14], Chiralpak AD (Daicel Chemical Industries, Tokyo, Japan) [15], and Chiralcel ODRH (Chiral Technologies Europe, France) [16] coupled to an HPLC system with fluorescence detection have been described for the analysis of Carvedilol enantiomers in plasma. Capillary electrophoresis using hydroxypropyl-beta-cyclodextrin as chiral selector has also been used for the enantioselective analysis of Carvedilol in serum using ultraviolet detector [17], or laser-induced fluorescence detector [18].

To the best of our knowledge, this is the first report to develop and validate a simple and efficient HPLC method using Phenomenex Lux Cellulose-4 column as chiral stationary phase and UV detection for the analysis of S(-)-Carvedilol from API and marketed formulation of racemic Carvedilol.

\section{Materials and Methods}

\subsection{Chemicals}

Racemic Carvedilol in the form of Active Pharmaceutical Ingredient (API) was gifted by Symed labs Ltd. (Medak, India). S(-)-Carvedilol ((S)-CAR) and R(+)-Carvedilol ((R)-CAR) were purchased from the Toronto Pharmaceuticals (Canada). Carvedilol tablets IP 3.125 mg (CARCA), manufactured by Intas Pharmaceuticals (East Sikkim, India) were purchased. HPLC grade solvents like n-Heptane, Isopropanol and Methanol were purchased from Sigma Aldrich Chemicals Pvt. Ltd. (Maharashtra, India). Syringe-driven PVDF hydrophilic membrane filters of pore size $0.22 \mu \mathrm{m}$ were purchased from HiMEDIA Laboratories Pvt. Ltd. (Mumbai, India).

\subsection{Equipment}

It consists of Ultra Fast Liquid Chromatograph of Shimadzu (Kyoto, Japan) equipped with binary pump (LC 20AD), UV/Visible detector (LC 20A) and Rheodyne injector port. The output signal was monitored and processed using Lab solutions software. Lux Cellulose-4 chiral column $(250 \times 4.6 \mathrm{~mm}$; $5 \mu$ particle size $)$ was purchased from Phenomenex (USA).

\subsection{Standard Solution Preparation}

Stock solutions of racemic Carvedilol, (S)-CAR and (R)-CAR of concentration $0.1 \mathrm{mg} / \mathrm{ml}$ were prepared by dissolving accurately weighed respective standard drugs in HPLC grade Methanol, individually.

\subsection{Sample Preparation}

Twenty tablets of CARCA were weighed and then finely powdered. An accurately weighed portion of the powder, equivalent to about $10 \mathrm{mg}$ of Carvedilol, was transferred to a $100 \mathrm{ml}$ volumetric flask and $40 \mathrm{ml}$ of Methanol was added. Then the volumetric flask was shaken mechanically for 5 minutes, sonicated for 10 min 
and diluted to volume with Methanol. $1 \mathrm{ml}$ of this solution was transferred to a $100 \mathrm{ml}$ volumetric flask and diluted to volume with Methanol. A portion of this solution was filtered through syringe-driven PVDF hydrophilic membrane filter of pore size $0.22 \mu \mathrm{m}$ and which was used as sample.

\section{Method Validation}

According to the ICH guidelines, the developed method was validated to assure the reliability of the results of the analysis for different parameters like system suitability, linearity, limit of detection (LOD), limit of quantification (LOQ), accuracy, precision and robustness [19].

\subsection{System Suitability}

The system suitability was determined by calculating retention factor, separation factor, resolution factor and tailing factor of enantiomers peaks resulted for the HPLC method analysis of racemic Carvedilol. The retention factor $(k)$ was calculated as $k=\left(t_{\mathrm{R}}-t_{\mathrm{M}}\right) / t_{\mathrm{M}}$, where, $t_{\mathrm{R}}$ refer to the retention time of the analyte and $t_{\mathrm{M}}$ refer to the elution time of the non-retained components. The separation factor $(\alpha)$ was calculated as the ratio of retention factors, $\alpha=k_{2} / k_{1}$. The resolution factor $\left(\mathrm{R}_{\mathrm{s}}\right)$ was calculated as $\mathrm{R}_{\mathrm{s}}=2\left(t_{2}-t_{1}\right) /\left(w_{1}+w_{2}\right)$, where, $t_{1}, t_{2}$ refer to the retention time of the first and second enantiomers; $w_{1}$ and $w_{2}$ are the peak widths for the first and second eluting enantiomers, respectively. Tailing factor ( $T$ ) was calculated as $T=\mathrm{W}_{0.05} / 2 \mathrm{f}$ where, $\mathrm{W}_{0.05}$ is the width of peak at $5 \%$ height from base line and $\mathrm{f}$ is the distance from peak maximum to the leading edge of the peak.

\subsection{Linearity}

Linearity was assessed by plotting calibration curve of (S)-CAR. For this, five different concentration solutions of (S)-CAR like 1, 5, 10, 50, and $100 \mathrm{ng} / \mathrm{ml}$ were prepared from the stock solution using Methanol as diluent. The calibration curve was obtained by plotting peak area versus concentration, using the least squares method. Linearity was checked for three consecutive days in the same concentration range from the same stock solution. The percentage relative standard deviation (RSD) of the regression coefficient was calculated.

\subsection{LOD}

LOD was calculated using the following formula;

$$
\mathrm{LOD}=3.3 \sigma / \mathrm{S}
$$

where $\sigma$ is the standard deviation of the response and $S$ is the slope of the calibration curve.

\subsection{LOQ}

LOQ was calculated using the following formula;

$$
\mathrm{LOQ}=\frac{10 \sigma}{S}
$$

where $\sigma$ is the standard deviation of the response and $S$ is the slope of the calibration curve.

\subsection{Accuracy}

Accuracy was determined by the standard addition method. Previously analyzed samples of CARCA ( $1 \mu \mathrm{g} / \mathrm{ml})$ were added up with $50 \%, 100 \%$, and $150 \%$ of standard (S)-CAR, separately. Each sample was prepared in triplicate $(\mathrm{n}=3)$ and all the samples were analyzed by the proposed method. Recovery (\%), RSD (\%), and standard error (SE) were calculated.

\subsection{Precision}

Precise method should have the reproducibility and was determined by measuring repeatability (intra-day) and intermediate precision (inter-day precision) of peak areas of the enantiomer. In order to determine the repeatability of the method, three different concentration solutions of (S)-CAR like 5, 10, $50 \mathrm{ng} / \mathrm{ml}$ were prepared in 
triplicate $(\mathrm{n}=3)$ and were analyzed by the proposed method. The intermediate precision was determined by analyzing six samples $(\mathrm{n}=6)$ of $5 \mathrm{ng} / \mathrm{ml}(\mathrm{S})$-CAR solution on three consecutive days.

\subsection{Robustness}

To determine robustness of the method, experimental conditions were purposely altered, and after analysis changes in retention time of the (S)-CAR was observed. The effect of change in flow rate on retention time of (S)-CAR was studied by changing the mobile phase flow rate to $0.9 \mathrm{ml} / \mathrm{min}$ as well as $1.1 \mathrm{ml} / \mathrm{min}$ instead of 1 $\mathrm{ml} / \mathrm{min}$, while the other chromatographic conditions were held constant. The effect of temperature on retention time of the enantiomer was studied at $38^{\circ} \mathrm{C}$ and $42^{\circ} \mathrm{C}$ instead of $40^{\circ} \mathrm{C}$ while the other mobile phase components were held constant, as stated in chromatographic condition section, Table 1.

\section{Results and Discussion}

Various solvent mixtures were tried for the enantioselective analysis of Carvedilol with good resolution. However, Isopropanol:n-Heptane in the ratio 60:40 (v/v) was given well-resolved sharp peaks with very good symmetry. The flow rate was set depending on the resolution factor, peak shape, tailing factor and time required for the analysis. Racemic Carvedilol (API), racemic Carvedilol tablet formulation (CARCA), S(-)-enantiomer $((\mathrm{S})-\mathrm{CAR})$ and $\mathrm{R}(+)$-enantiomer ((R)-CAR) were analyzed by this method and their chromatograms were shown in Figures 1-4, respectively. The retention time of standard (R)- and (S)-CAR were found as 7.490 and 9.397, respectively while the retention time of (R)- and (S)-enantiomers of racemic Carvedilol were found as 7.389 and

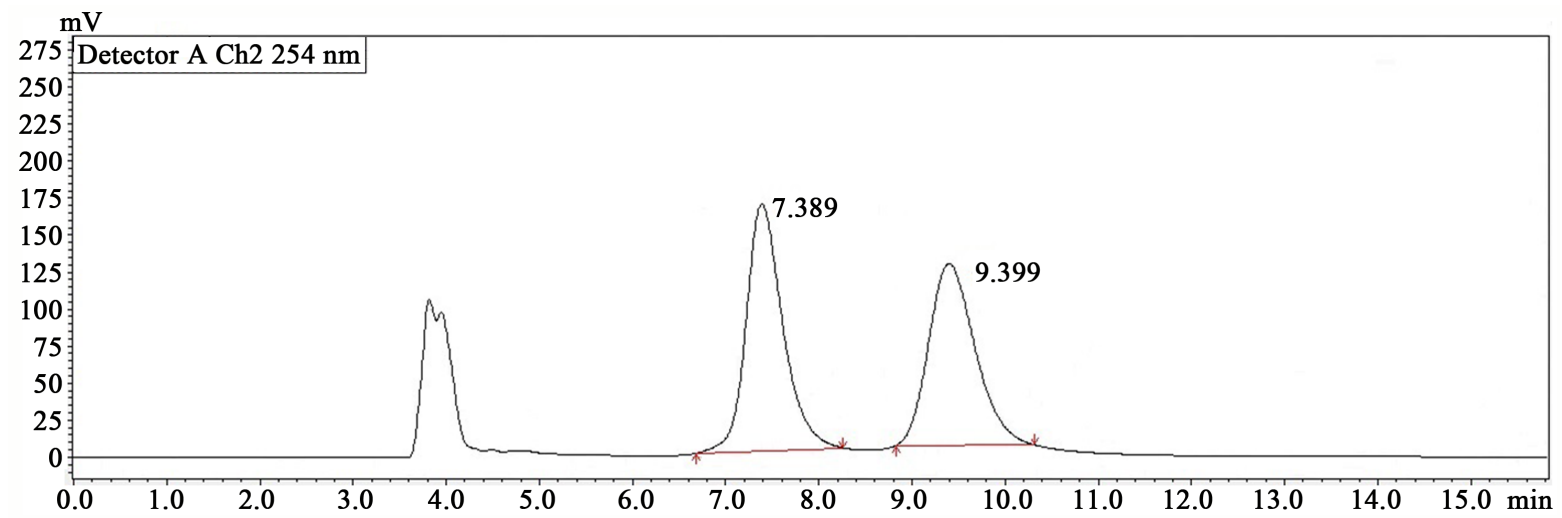

Figure 1. Chromatogram of racemic Carvedilol (100 ng/ml).

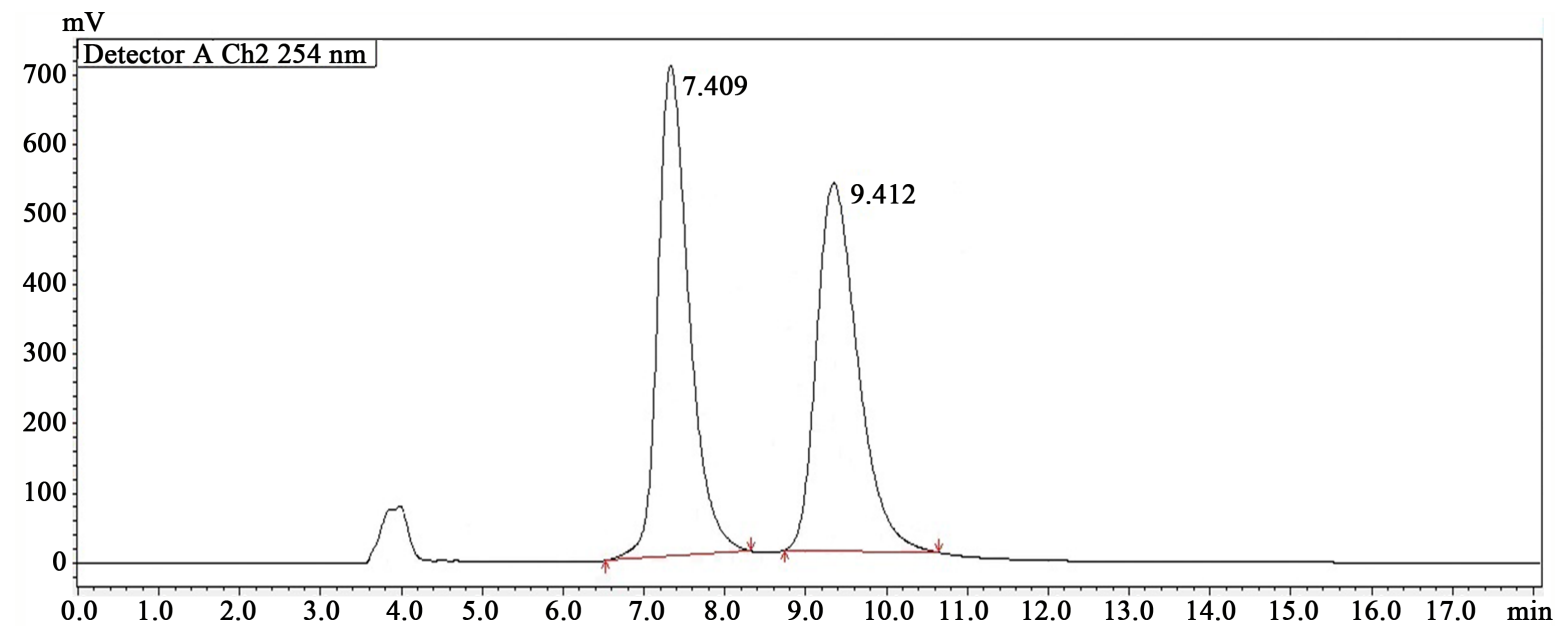

Figure 2. Chromatogram of CARCA $(1 \mu \mathrm{g} / \mathrm{ml})$. 
$\mathrm{mV}$

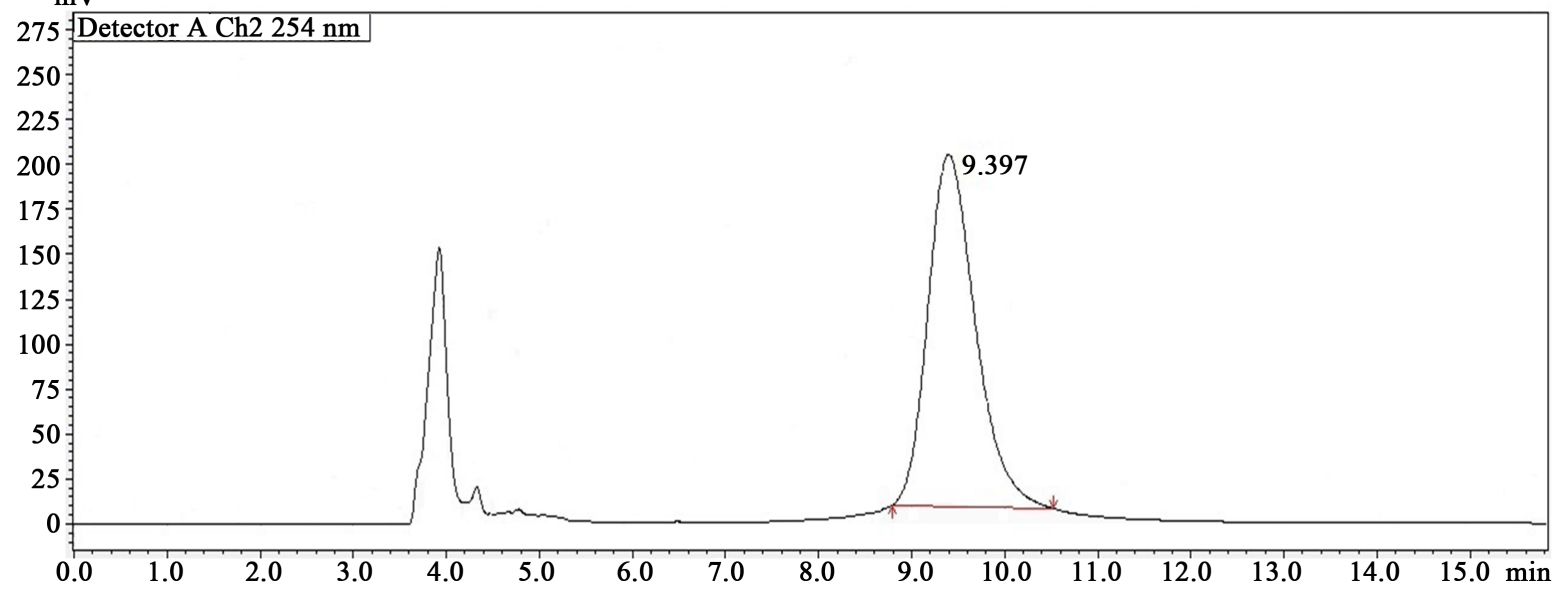

Figure 3. Chromatogram of (S)-CAR (100 ng/ml).

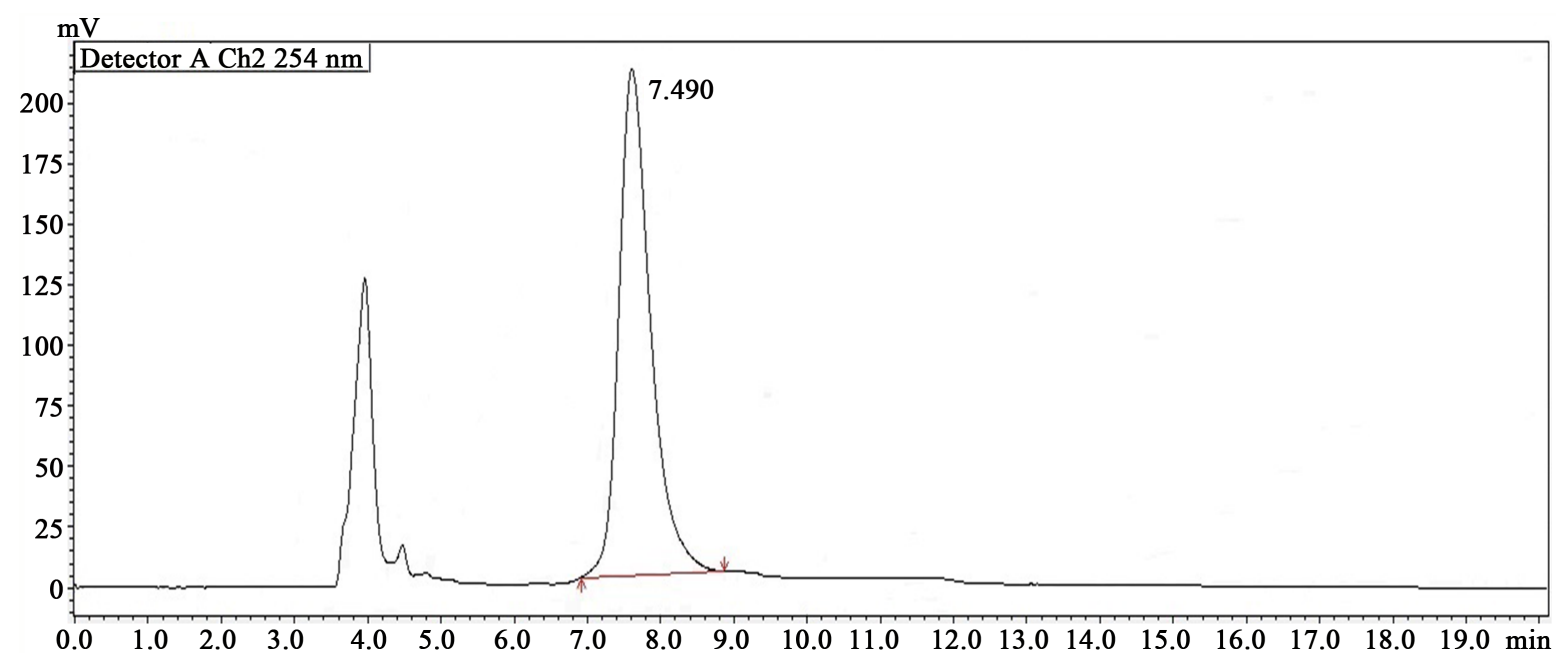

Figure 4. Chromatogram of (S)-CAR (100 ng/ml).

Table 1. Chromatographic conditions.

\begin{tabular}{cc}
\hline Stationary phase & Phenomenex Lux Cellulose-4 column $(250 \times 4.6 \mathrm{~mm} ; 5 \mu$ particle size $)$ \\
Mobile phase & Isopropanol:n-Heptane $(60: 40)$ \\
Flow rate & $1 \mathrm{ml} / \mathrm{min}$ \\
Injection volume & $20 \mu \mathrm{L}$ \\
Column temperature & $40^{\circ} \mathrm{C}$ \\
Detection wavelength & $254 \mathrm{~nm}$ \\
\hline
\end{tabular}

9.399, respectively. The retention time of the (R)- and (S)-enantiomers of racemic Carvedilol marketed formulation (CARCA) were found as 7.409 and 9.412, respectively. As the retention time of standard enantiomers were comparable to that of the enantiomers of the racemic Carvedilol and CARCA, the present method can be used for the enantioselective analysis of Carvedilol from various marketed formulations.

\subsection{Validation of the Method}

System suitability parameters were evaluated and the values were shown in Table 2. The separation factor and 
Table 2. System suitability parameters.

\begin{tabular}{cccc}
\hline Parameters & Limits as per ICH guidelines & \multicolumn{2}{c}{ Values obtained } \\
\hline Separation factor $(\alpha)$ & $>1$ & & 1.42 \\
Resolution factor $\left(\mathrm{R}_{\mathrm{s}}\right)$ & $>1.5$ & (S)-CAR & 1.91 \\
& & 0.31 & 0.23 \\
Tailing factor $(\mathrm{T})$ & $\leq 2$ & 2.82 & 2.00 \\
Retention factor $(\mathrm{k})$ & $1-10$ & $\mathrm{R})$-CAR \\
\hline
\end{tabular}

resolution factor of enantiomers of the racemic Carvedilol were found as 1.42 and 1.91, respectively. These values were greater than the minimum values mentioned in ICH guidelines and hence the method proved to provide good resolution of enantiomers of racemic Carvedilol. As per ICH guidelines, the tailing factor should be less than 2 and the present method has shown tailing factors of (R)- and (S)-CAR as 0.23 and 0.31 , respectively. Hence the method offers well resolved sharp peaks for the Carvedilol enantiomers with good symmetry. The retention factor is often used to describe the migration rate of an analyte on a column and as per ICH guidelines it should be between 1 and 10. The method, has given retention factors of (R)- and (S)-CAR as 2 and 2.82, respectively and were found to be in the limit of ICH guidelines. Hence the both enantiomers will take less time for elution and the analysis will complete in short duration of time. All the parameters were proved that the chromatographic system used was suitable for the enantioselective analysis of Carvedilol from API and formulations.

\subsubsection{Linearity}

The calibration curve of (S)-CAR was plotted using peak area vs. concentration and was shown in Figure 5. The experiment was repeated for three times $(\mathrm{n}=3)$ and the relative standard deviation (RSD) was calculated for regression coefficient. Retention time, slope, intercept, regression coefficient along with \%RSD values of (S)CAR calibration curve were given in Table 3. The method has shown good linearity for (S)-CAR $\left(r^{2}=0.9998\right)$ in the concentration range of $1-100 \mathrm{ng} / \mathrm{ml}$. As the \%RSD of regression coefficient was found to be very less $(<2 \%)$, which is within in the limits of ICH guidelines and the method's linearity was proved to be reproducible.

\subsubsection{LOD and LOQ}

There are many methods available like HPLC with fluorescence detection (HPLC-FLD), Capillary Electrophoresis with laser-induced fluorescence detection (CE-FLD), LC/LC-FLD, HPLC/MS/MS for the enantioselective analysis of Carvedilol from human plasma, serum and urine employing either chiral derivatizing agents or various chiral stationary phases [8]-[18]. Though some of the methods yielded less LOD and LOQ range for analysis of Carvedilol enantiomers from biological samples, none of them explain the enantioselective analysis of Carvedilol from API and marketed formulations by HPLC using cellulose based chiral column, employing UV detection. The LOD and LOQ values of (S)-CAR found by this method were shown in Table 3. The low values of LOD and LOQ indicates that the method can be used for detection and quantification of (S)-CAR over a very wide range of concentrations.

\subsubsection{Accuracy}

Accuracy of the method was ascertained by recovery method. For this purpose previously analyzed CARCA test solutions of concentration $1 \mathrm{\mu g} / \mathrm{ml}$ were added up with $50 \%, 100 \%, 150 \%$ of standard (S)-CAR, separately. The samples were prepared in triplicate $(n=3)$ and analysis was carried out by the proposed method. The \% recoveries along with relative standard deviation (RSD) and standard error (SE) values were shown in Table 4. The overall average \% recovery of (S)-CAR was found as $99.18 \%$ with very less standard deviation and negligible standard error, which proves the developed method as accurate.

\subsubsection{Precision}

To determine intra-day precision, three different concentrations of (S)-CAR (5, 10 and $50 \mathrm{ng} / \mathrm{ml})$ were prepared in triplicate $(\mathrm{n}=3)$ and analyzed at specific time intervals in the same day. The Coefficient of Variance (\% CV) 


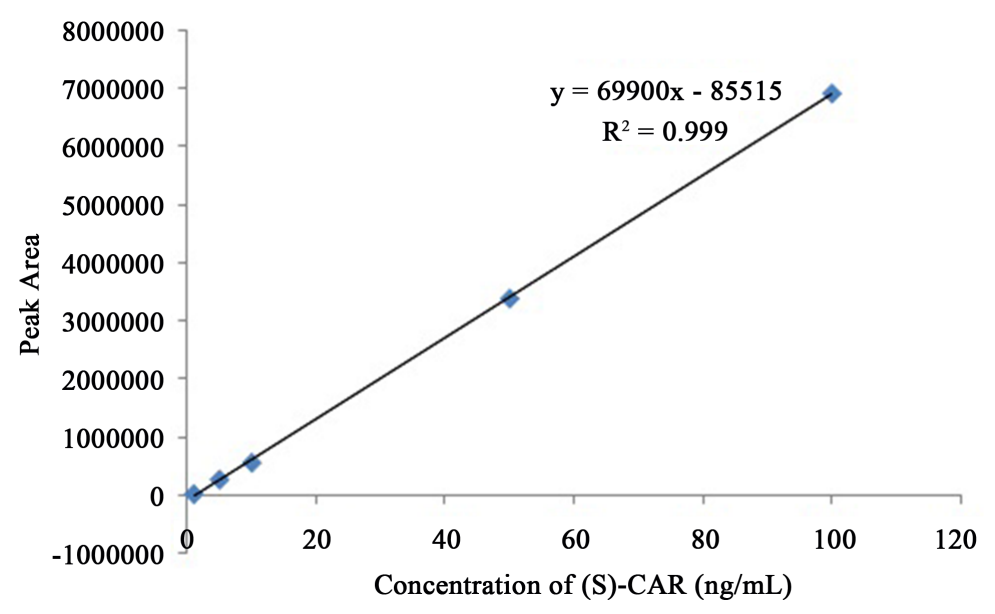

Figure 5. Calibration curve of (S)-CAR.

Table 3. Linearity of (S)-CAR.

\begin{tabular}{ccccccc}
\hline Enantiomer & Retention time & LOD $(\mathrm{ng} / \mathrm{ml})$ & LOQ $(\mathrm{ng} / \mathrm{ml})$ & Slope & Intercept & Regression coefficient \pm RSD \\
\hline (S)-CAR & 9.397 & 1.08 & 3.29 & 69900 & 85515 & $0.9998 \pm 0.003$ \\
\hline
\end{tabular}

Table 4. Accuracy of (S)-CAR.

\begin{tabular}{cccc}
\hline Concentration of CARCA $(\mu \mathrm{g} / \mathrm{ml})$ & Added \% of (S)-CAR & \% Recovery (RSD) \pm SE & Average \% recovery (RSD) \pm SE \\
\hline \multirow{2}{*}{10} & 50 & $98.16(0.13) \pm 0.07$ & \\
& 100 & $99.74(0.18) \pm 0.11$ & $99.18(0.18) \pm 0.10$ \\
\hline
\end{tabular}

was calculated for all the samples and the values along with RSD and SE were given in Table 5. All the three different concentration samples of (S)-CAR were shown insignificant RSD and SE in their Coefficient of Variance, which indicates that the method has good repeatability.

For inter-day precision analysis, six samples of $(\mathrm{S})$-CAR, $5 \mathrm{ng} / \mathrm{ml}$ concentration solution $(\mathrm{n}=6)$, were prepared and analyzed for three consecutive days. Average \% Coefficient of Variance of (S)-CAR on each day was calculated and given along with their RSD and SE in Table 6. The RSD and SE of \% CV of (S)-CAR for all the three consecutive days was found to be less than $2 \%$, which is the limit as per ICH guidelines and hence the method proved to be precise.

\subsubsection{Robustness}

Chromatographic conditions of the method were altered briefly and analysis of (S)-CAR was performed for three times $(n=3)$. Changes in retention time were recorded and the \% RSD of retention time of (S)-CAR respective to change in each parameter was shown in Table 7. As the \% RSD of retention time of (S)-CAR for each change in parameters was less than $2 \%$, which is the limit as per ICH guidelines and hence the method proved to be robust. Hence slight changes in temperature and mobile phase flow rate will not affect the method in enantioselective analysis of Carvedilol from API and formulations.

\section{Conclusion}

The present work was intended for the analysis of S(-)-Carvedilol from API and formulations, both qualitatively and quantitatively. For this purpose a simple and rapid chiral HPLC method using cellulose-based stationary phase was developed and validated. As the overall cardioprotective action of (S)-CAR is more than that of the (R)-CAR, validation of the method was focused only on (S)-CAR. Statistical analysis results of the method validation revealed that the method has high accuracy with a good precision. Hence the method is reliable and 
Table 5. Intra-day precision (repeatability) of (S)-CAR.

\begin{tabular}{cccc}
\hline \multirow{2}{*}{$\begin{array}{c}\text { Concentration of } \\
(\mathrm{S})-\text { CAR }(\mathrm{ng} / \mathrm{ml})\end{array}$} & $0 \mathrm{hr}$ CV $(\% \mathrm{RSD}) \pm \mathrm{SE}$ & $5^{\text {th }} \mathrm{hr}$ \\
\cline { 2 - 4 } 5 & $99.66(0.015) \pm 0.008$ & $99.54(0.025) \pm 0.014$ & $99.41(0.02) \pm 0.011$ \\
10 & $99.61(0.025) \pm 0.014$ & $99.38(0.045) \pm 0.026$ & $99.17(0.055) \pm 0.032$ \\
50 & $99.62(0.045) \pm 0.026$ & $99.39(0.07) \pm 0.04$ & $99.21(0.08) \pm 0.046$ \\
\hline
\end{tabular}

Table 6. Inter-day precision (intermediate precision) of (S)-CAR.

\begin{tabular}{cccc}
\hline \multirow{2}{*}{\begin{tabular}{c}
$(\mathrm{S})-\mathrm{CAR}$ Concentration $(\mathrm{ng} / \mathrm{ml})$ \\
\cline { 2 - 3 }
\end{tabular}} & $1^{\text {st }}$ day & Average \% CV (\% RSD) \pm SE & $3^{\text {rd }}$ day \\
\hline 5 & $99.64 \%(0.02) \pm 0.01$ & $98.96 \%(0.06) \pm 0.02$ & $98.43 \%(0.04) \pm 0.01$ \\
\hline
\end{tabular}

Table 7. Robustness of the method.

\begin{tabular}{|c|c|c|c|}
\hline Parameters & Normal condition & Condition opted & $\%$ RSD of retention time of (S)-CAR \\
\hline Flow rate & $1 \mathrm{ml} / \mathrm{min}$ & $\begin{array}{l}0.9 \mathrm{ml} / \mathrm{min} \\
1.1 \mathrm{ml} / \mathrm{min}\end{array}$ & $\begin{array}{l}0.02 \\
0.02\end{array}$ \\
\hline Column temperature & $40^{\circ} \mathrm{C}$ & $\begin{array}{l}38^{\circ} \mathrm{C} \\
42^{\circ} \mathrm{C}\end{array}$ & $\begin{array}{l}0.03 \\
0.02\end{array}$ \\
\hline
\end{tabular}

convenient for routine quality control and stability assays of (S)-CAR in both API and marketed tablet formulations.

\section{Acknowledgements}

Authors are thankful to SERB, DST, New Delhi for the financial assistance. Authors are also thankful to Symed labs Ltd., Medak, India for the kind gift of racemic Carvedilol (API).

\section{References}

[1] Phuong, N.T., Lee, B.J., Chol, J.K., Kang, J.S. and Kwon, K. (2004) Enantioselective Pharmacokinetics of Carvedilol in Human Volunteers. Archives of Pharmacal Research, 27, 973-977. http://dx.doi.org/10.1007/BF02975853

[2] Gagyi, L., Gyeresi, A. and Kilar, F. (2008) Role of Chemical Structure in Stereoselective Recognition of Beta-Blockers by Cyclodextrins in Capillary Zone Electrophoresis. Journal of Biochemical and Biophysical Methods, 70, 1268-1275. http://dx.doi.org/10.1016/j.jbbm.2007.10.004

[3] Lamprecht, G., Gruber, L., Staschitzky, K. and Lindner, W. (2002) Enantioselective Analysis of (R)- and (S)-Carvedilol in Human Plasma by High Performance Liquid Chromatography. Chromatographia, 56, S25-S29. http://dx.doi.org/10.1007/BF02494109

[4] Oldham, H.G. and Clarke, S.E. (1997) In Vitro Identification of the Human Cytochrome P450 Enzymes Involved in the Metabolism of R(+)- and S(-)-Carvedilol. Drug Metabolism and Disposition, 25, 970-977.

[5] Nakajima, T., Ma, J., Iida, H., Iwasawa, K., Jo, T., Omata M., et al. (2003) Inhibitory Effects of Carvedilol on Calcium Channels in Vascular Smooth Muscle Cells. Japanese Heart Journal, 44, 963-978. http://dx.doi.org/10.1536/jhj.44.963

[6] Jia, H. and Chan, H.K. (2010) Comparing the Effects of Carvedilol Enantiomers on Regression of Established Cardiac Hypertrophy Induced by Pressure Overload. Laboratory Animal Research, 26, 75-82. http://dx.doi.org/10.5625/lar.2010.26.1.75

[7] Takekuma, Y., Yagisawa, K. and Sugawara, M. (2012) Mutual Inhibition between Carvedilol Enantiomers during Racemate Glucuronidation Mediated by Human Liver and Intestinal Microsomes. Biological and Pharmaceutical Bulletin, 35, 151-163. http://dx.doi.org/10.1248/bpb.35.151

[8] Bhushan, R. and Dixit, S. (2012) Enantioresolution of Five $\beta$-Blockers by Reversed-Phase High Performance Liquid Chromatography Using Fifteen Chiral Derivatizing Reagents Having Amino Acids or Their Amides as Chiral Auxiliaries on a Cyanuric Chloride Platform. Biomedical Chromatography, 26, 239-246. http://dx.doi.org/10.1002/bmc.1653 
[9] Yang, E., Wang, S., Kratz, J. and Cyronak, M.J. (2004) Stereoselective Analysis of Carvedilol in Human Plasma Using HPLC/MS/MS after Chiral Derivatization. Journal of Pharmaceutical and Biomedical Analysis, 36, 609-615. http://dx.doi.org/10.1016/j.jpba.2004.07.008

[10] Zakrzewski-Jakubiaka, M., de Denusb, S., Leblancc, M.-H., Whiteb, M. and Turgeon, J. (2010) Enantioselective Quantification of Carvedilol in Human Plasma by HPLC in Heavily Medicated Heart Failure Patients. Journal of Pharmaceutical and Biomedical Analysis, 52, 636-641. http://dx.doi.org/10.1016/j.jpba.2010.02.002

[11] Spahn, H., Henke, W., Langguth, P., Schloos, J. and Mutschler, E. (1990) Measurement of Carvedilol Enantiomers in Human Plasma and Urine Using S-Naproxen Chloride for Chiral Derivatization. Archiv der Pharmazie, 323, 465-469. http://dx.doi.org/10.1002/ardp.19903230805

[12] Peccinini, R.G., Ximenes, V.F., Cesarino, E.J. and Lanchote, V.L. (2008) Stereoselective Analysis of Carvedilol in Human Plasma and Urine Using HPLC after Chiral Derivatization. Biopharmaceutics \& Drug Disposition, 29, 280288. http://dx.doi.org/10.1002/bdd.613

[13] Wang, S., Cyronak, M. and Yang, E. (2007) Does a Stable Isotopically Labeled Internal Standard Always Correct Analyte Response? A Matrix Effect Study on a LC/MS/MS Method for the Determination of Carvedilol Enantiomers in Human Plasma. Journal of Pharmaceutical and Biomedical Analysis, 43, 701-707. http://dx.doi.org/10.1016/j.jpba.2006.08.010

[14] Clohs, L. and McErlane, K.M. (2003) Comparison between Capillary Electrophoresis and High Performance Liquid Chromatography for the Stereoselective Analysis of Carvedilol in Serum. Journal of Pharmaceutical and Biomedical Analysis, 31, 407-412. http://dx.doi.org/10.1016/S0731-7085(02)00609-X

[15] Saito, M., Kawana, J., Ohno, T., Kaneko, M., Mihara, K., Hanada, K., et al. (2006) Enantioselective and Highly Sensitive Determination of Carvedilol in Human Plasma and Whole Blood after Administration of the Racemate Using Normal-Phase High-Performance Liquid Chromatography. Journal of Chromatography B, 843, 73-77. http://dx.doi.org/10.1016/j.jchromb.2006.05.018

[16] Medvedovici, A., Albu, F., Georgita, C., Sora, D.I., Galaon, T., Udrescu, S., et al. (2007) Achiral-Chiral LC/LC-FLD Coupling for Determination of Carvedilol in Plasma Samples for Bioequivalence Purposes. Journal of Chromatography B, 850, 327-335. http://dx.doi.org/10.1016/j.jchromb.2006.12.004

[17] Clohs, L. and McErlane, K.M. (2001) Development of a Capillary Electrophoresis Assay for the Determination of Carvedilol Enantiomers in Serum Using Cyclodextrins. Journal of Pharmaceutical and Biomedical Analysis, 24, 545554. http://dx.doi.org/10.1016/S0731-7085(00)00468-4

[18] Behn, F., Michels, S., Laer, S. and Blaschke, G. (2001) Separation of Carvedilol Enantiomers in Very Small Volumes of Human Plasma by Capillary Electrophoresis with Laser-Induced Fluorescence. Journal of Chromatography B, 755, 111-117. http://dx.doi.org/10.1016/S0378-4347(01)00045-7

[19] ICH Harmonised Tripartite Guideline (2005) Validation of Analytical Procedures: Text and Methodology Q2(R1). International Conference on Harmonisation of Technical Requirements for Registration of Pharmaceuticals for Human Use, Geneva, 2005, 1-13. 